\title{
TWO NEW MISSISSIPPI ANTS OF THE SUBGENUS COLOBOPSIS.
}

\section{By M. R. Sмiтh.}

Mississippi State Plant Board, A. \& M. College, Mississippi.

The subgenus Colobopsis is a division of the genus Camponotus. It includes those ants the major workers and females of which have anteriorly truncated heads. The truncated area may be concave or blunt, in either case the sides are always marginate and well defined. The characters mentioned are so distinct that one has no difficulty in assigning ants of this type to the proper genus.

The subgenus Colobopsis in North America seems to have very few species, most of the known forms having been described by Dr. W. M. Wheeler in a paper published in $1904 .{ }^{1}$ In this paper the following species are recorded as occuring in North America, namely: Colobopsis impressus Roger, Colobopsis pylartes Wheeler, Colobopsis abditus var. etiolatus Wheeler. Since that time Dr. Wheeler has described and added another variety to the known North American forms, this species being Colobopsis pylartes var. hunteri.

Because of the fact that these ants nest in galls, twigs of trees and the stems of plants they are seldom taken by collectors. This partly accounts for the few known forms. Their habits are also imperfectly known.

In Mississippi three distinct species of Colobopsis have been taken, two of which are being described as new in this paper. The writer would feel somewhat hesitant about describing these as new if Dr. Wheeler had not examined the specimens and reviewed the descriptions. The third species of Colobopsis found in Mississippi is one that can be assigned to C. impressus. All three of these forms are very distinct and it is impossible

1The American Ants of the Subgenus Colobopsis; Bulletin American Museum Natural History Vol. 20, Article 10, pp. 139-158. 
for one to confuse them. C. impressus, which has a head with distinctly parallel sides, can easily be distinguished from the other two species both of which have heads with the sides diverging anteriorly.

In this section of the state $C$. pylartes fraxinicola and $C$. mississippiensis nest in the twigs of white ash, Fraxinus americana Linn. and are rather common species, particularly the latter, which can be found in the twigs of ash with very little effort. Without doubt these species must feed to a large extent if not altogether, on the honey dew excreted by aphids, scale insects, etc. for the writer has on a number of occasions seen the workers lapping up this substance from the leaves of trees and plants. C. mississippiensis seems to breed here thruout the winter. Nests examined at various dates during the season always contained eggs and larvæ. Since the winters in Mississippi are rather mild and the ants are well protected from exposure, this is to be expected.

The writer is very grateful to Dr. W. M. Wheeler for examining the specimens described here and for reviewing the technical descriptions. To Professor R. W. Harned the writer wishes to express his appreciation for encouragement given in the study of these and other Mississippi ants and for the generous allotment of time for such work.

\section{Colobopsis mississippiensis sp. nov.}

\section{Soldier. Length, 4.5-5mm.}

Head subcylindrical, from above rectangular, longer than broad, sides divergent anteriorly, occipital border convex, anterior truncated surface deeply concave, its edges sharply marginate along the sides but less so in the clypeal region. Mandibles small, with flattened ventral surfaces, 4 -toothed with a short toothless proximal portion to the blade. Clypeus on the truncated surface about one and a half times longer than broad, upper portion on the truncated area more divergent than the lower portion. There is a distinct median keel running the full 
length of the clypeus. On the front, carinæ far apart, with sides converging anteriorly. Eyes moderate, oblong, convex. Antennal scapes curved, slender at the base, gradually enlarging toward their tips. All the funicular joints except the first subequal, first joint almost equal to the next two in length. Thorax robust, pronotum about as broad as long, convex. Meso-epinotal constriction distinct but not deep. Epinotal base and declivity meeting in such a way as to form a decided angle. Petiole low, convex and rounded in front and above, flattened behind, the posterior dorsal edge of the node faintly impressed in the middle but not excised or emarginate. Gaster oblong. Legs short, femora compressed, anterior pair distinctly dilated.

Mandibles and anterior two thirds of head subopaque, the former obscurely longitudinally rugose, the latter coarsely and irregularly reticulate-rugose, with punctate interrugal spaces. On the cheeks and front the sculpture gradually passes over into umbilicately punctate, shallow and scattered foveolæ.

Cheeks and anterior dorsal surface of the head with short, erect, blunt yellowish hairs. There are a few short hairs on the tips of the scapes and femora. Vertex of the head and dors 1 and sternal sides of the gaster with longer, erect, whitish hairs ${ }^{*}$

Anterior two thirds of head including antennæ reddish brown, posterior portion of head blackish brown; thorax and appendages brown; abdomen black.

Worker. Length 3.5-4 mm.

Head longer than broad, a little broader behind than in front, occipital borders and cheeks convex. Mandibles small, 4-toothed. Clypeus nearly square, medianly keeled. Frontal carinæ converging anteriorly. Antennæ proportionately longer than in the soldier; scapes flattened, gradually enlarging toward their tips. Thorax similar to that of the soldier with the exception of the epinotum whose basal surface meets the declivity in such a manner as to form a sharp angle. Petiole low, robust, 
with convex anterior and superior surfaces, the posterior dorsal edge of node centrally impressed as in the soldier; posterior surface flat. Gaster oblong. Legs as in the soldier.

Body and appendages shining, distinctly shagreened, the head and thorax more coarsely than the gaster; the cheeks and upper surface of the head with scattered punctures.

Head, legs and gaster covered with delicate white appressed hairs. Clypeus, front, vertex, tips of scapes and femora with a few long, scattered, hairs.

Dark brown; head almost black, gaster black, thorax and appendages lighter than either.

The specimens on which these descriptions are based were taken at Starkville, Mississippi, on January 7th, 1922, in the twigs of white ash, Fraxinus americana Linn.

This seems to be a very common species of Colobopsis in Mississippi. In every instance observed it has been found nesting in the twigs of white ash. The ants mine out all of the soft portion of the twigs forming longitudinal galleries within the axes of the stems. The galleries may be from a few inches to over a foot in length. The young are reared within these galleries. Small entrance holes in diameter about the size of the soldiers' heads lead from the outside of the twigs to the galleries within. There may be from one to several entrance holes to a nest. No soldiers have been observed using their heads to block these holes as has been noticed in other species of the genus. The female must undoubtedly construct her nest alone and rear the first brood to maturity unaided, as the writer has on a number of occasions found dead or live queens alone in small galleries.

Colobopsis mississippiensis was so named because it is the most common species of the genus in Mississippi. It is very easily recognized by the deeply concave, truncated surface of the head. The sides of the truncated area are very sharp and well defined, except in the dorsal clypeal region. The head of this species when viewed from above has sides that are distinctly 
divergent anteriorly with the anterior area of the head very concave or hollowed out. This species seems to be somewhat variable in color. In some specimens the soldiers have abdomens with the basal segment yellowish, in others there is a faint yellowish band on the anterior portion of the second segment, in still others there is a combination of the two. There is variation in the color of the head and thorax, some specimens being much lighter than others. The writer hesitates to assign these speicmens to varieties based on color, especially in view of the fact that he has not seen material from many localities.

Colobopsis pylartes fraxinicola subsp. nov.

Soldier. Length, 4.5-5 mm.

Head subcylindrical, viewed from above only slightly longer than broad, noticeably wider in front than behind, with inflated cheeks; occipital border straight or faintly convex. Anterior truncated surface oblique, border blunt on sides of face and mandibles, on the clypeal and adjacent region the truncated passes into the dorsal surface thru a rounded angle. Mandibles with blunter ventral margins than those of mississippiensis, blade with 4 distinct teeth and a toothless proximal basal portion. Clypeus projecting above surface of truncated area, broader or more divergent above than below. Eyes, frontal carinæ and antennæ as in mississippiensis. Thorax short, robust. Meso-epinotal constriction distinct and pronounced. The angle formed by the junction of the basal surface of the epinotum and the declivity distinct. Petiole low, robust, with convex anterior and superior surfaces and flat posterior surface; the posterior margin of the superior surface deeply excised or emarginate. Gaster and legs as in mississippiensis.

Mandibles and anterior half of head subopaque, the former obscurely longitudinally rugose-punctate, the latter regularly and coarsely reticulate-rugose with punctate interrugal spaces. On the cheeks and front the sculpture gradually passes over into umbilicately punctate, shallow, scattered foveolæ. Posterior half of the head and the remainder of body shining, finely shagreened. 
Hairs yellowish short, erect and obtuse on the cheeks, longer and more tapering on front and vertex. Gaster above and below with scattered tapering hairs. There are a few short hairs at the tips of the scapes and femora.

Anterior half of head light yellowish, posterior half of head including antennæ dark brown, thorax and appendages brown, abdomen black, with base of first and second segment tinged with yellow.

Worker. Length, 3-3.5 mm.

Head longer than broad, broader behind than in front, with convex occipital border and somewhat less convex sides. Mandibles small, 4 toothed. Clypeus convex, almost square and not noticeably keeled. Antennal scapes flattened, gradually tapering from base to tip. Thorax very deeply constricted at the junction of meso-epinotum. The base of the epinotum in profile appears flattened and forms with the declivity a distinct angle. Petiole low, robust, with convex anterior and superior surfaces, the posterior margin of the latter deeply excised to form two distinct lateral teeth, the posterior surface of the petiole flattened. Gaster oblong. Legs similar to those of the soldier.

Body and appendages shining, distinctly shagreened, the head and thorax more coarsely than the gaster, the cheeks and upper surfaces of the head with scattered punctures.

Head, legs and gaster sparsely covered with delicate, white, appressed hairs. Clypeus, front, vertex, tips of antennæ and femora and the gastric segments with a few scattered and longer hairs.

Dark brown; head darker, mandibles, cheeks and appendages light brown, gaster black.

The ants on which these descriptions are based were collected at Starkville, Mississippi, on January 11, 1922. Like mississippiensis this subspecies has a fondness for nesting in white ash but has also been taken by Mr. Andrew Fleming at 
Sibley, Mississippi from the twigs of elder. The nesting habits of the two seem to be about the same. Besides the localities mentioned the writer has specimens from Columbus and A. \& M. College.

The soldier of this subspecies can be recognized by its peculiarly blunt head, the truncated area of which is oblique in profile. The clypeus on the truncated area projects above the surface very noticeably and it much broader above than below. The punctation and sculpturing on the anterior portion of the head is regular and distinct. When the head of the soldier is viewed from above it appears rectangular, very little broader than long, with divergent sides and inflated cheeks.

The workers can be distinguished by the very deep constriction at the meso-epinotum and by the prominent 2-toothed petiole, both of which are very different from those of mississippiensis.

The color in fraxinicola is variable as in the preceeding species, some specimens being very dark while others are lighter and have more yellow on the base of the gaster and the second segment. 

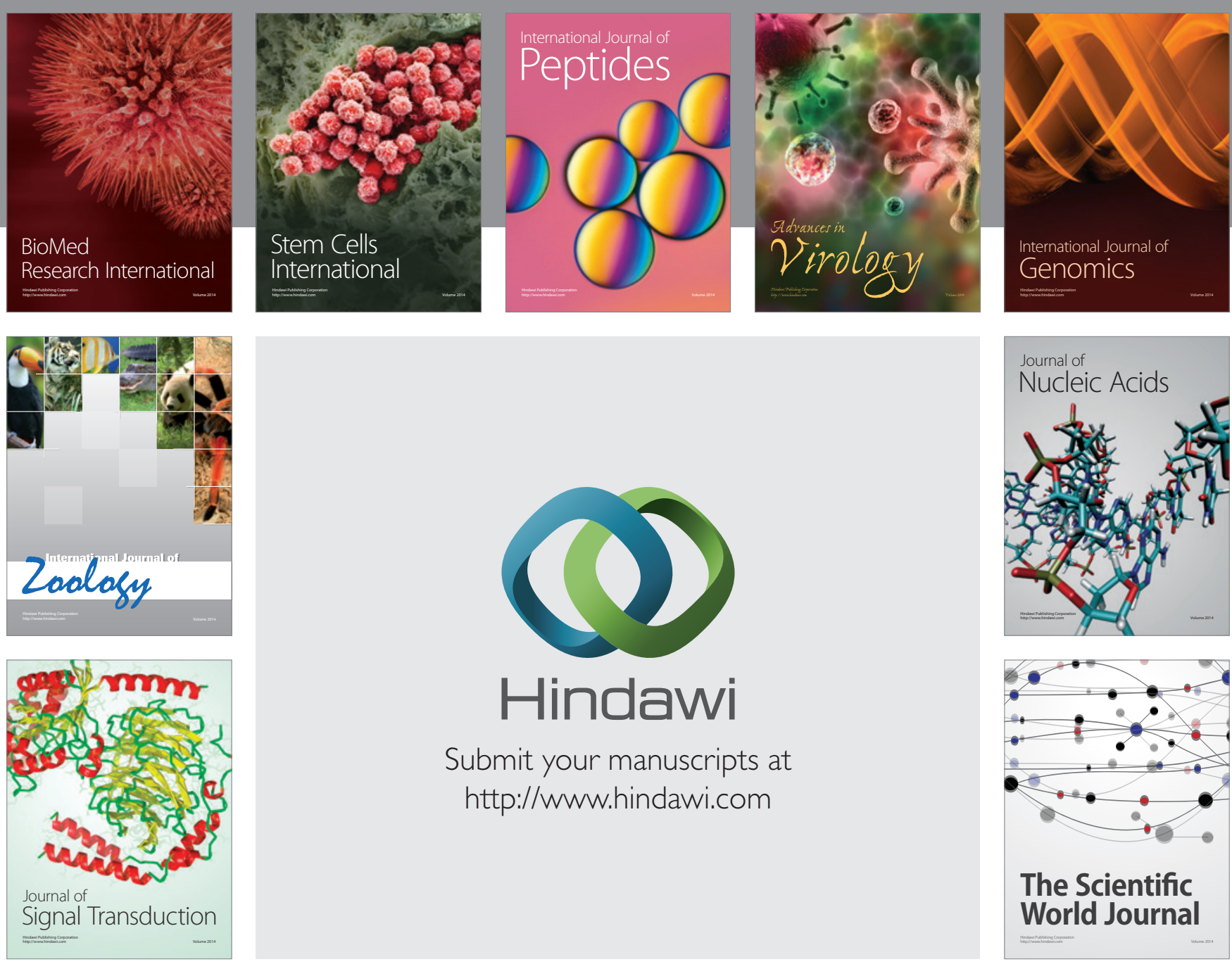

Submit your manuscripts at

http://www.hindawi.com
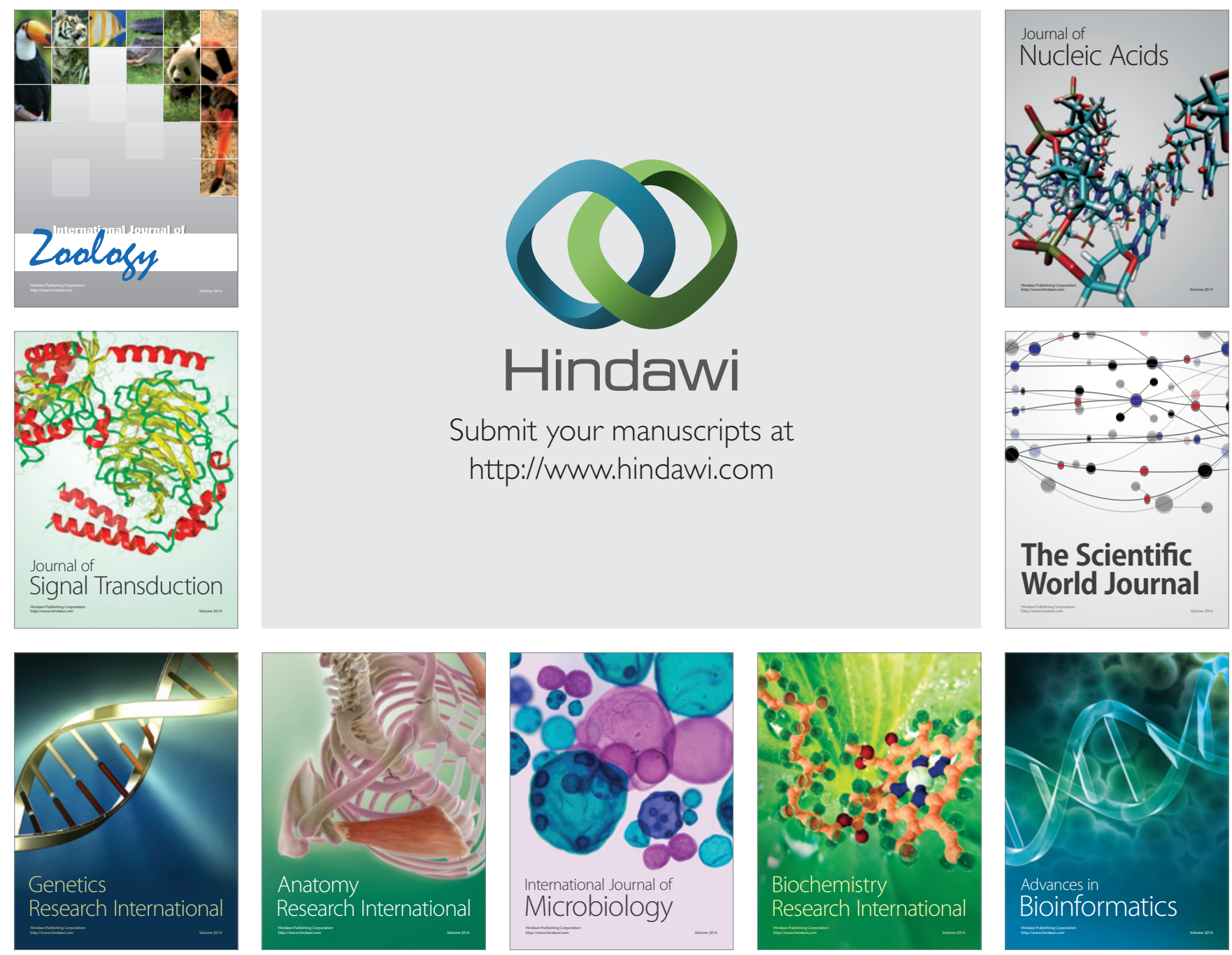

The Scientific World Journal
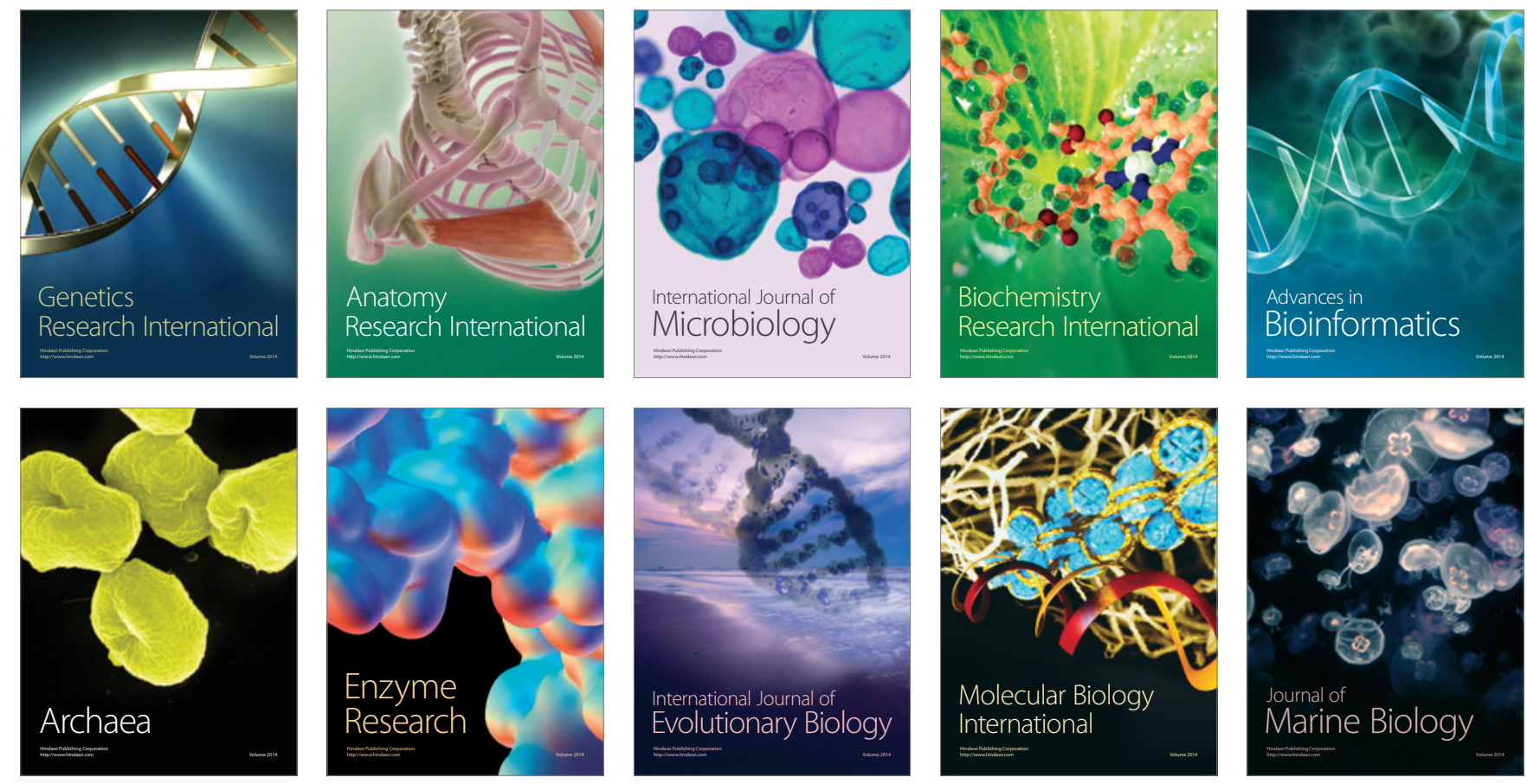